\title{
“Once mad is always mad”: Mental Health Service Users' Experience in the Nigeria Labour Market
}

\author{
Felicia O., Owadara \\ Faculty of Social Work, Fort Garry, University of Manitoba \\ 66 Vice Chancellor Road, R3T 2N2. Winnipeg, Manitoba
}

\begin{abstract}
Background: The dearth of literature on the labour market experience of Mental Health Service Users in Nigeria signifies the dire need to explore service users' perspectives on issues of employment.
\end{abstract}

Objective: This study explores the Mental Health Service User's experience on access to the Nigeria labour market.

Method: The study adopts an interpretive phenomenological analysis and conducts an unstructured interview method to investigate participants' experiences and the sense they make out of their daily struggles in seeking employment. Data were thematically coded and supported by participant's narratives.

Results: The findings generated two main themes with six additional subthemes: (1) The hindrance to the MHSU's economic participation is linked to hostility and discrimination, and institutional factors (the lack of credible response in policy and practice). Also, (2). close networks remain significant for the group's economic and social adjustment, but it is often not available for all in the labour market.

Conclusion: The paper increases our understanding of informal networks' crucial role when navigating the labour market and shows that it may have severe implications in how policy functions. A more comprehensive study is needed to examine the nature of the informal support system that facilitates access to some and ostracizes others' needs. Consideration should be given to the policy environment, the role and efficacy of the nongovernmental agencies, and the family networks system to understand hindrances to the engagement of MHSU.

Keywords: Economic participation, Mental Health, Discrimination, Disclosure, Policy

\section{INTRODUCTION}

$\mathrm{T}$ The notion of social justice and equity articulated in the Section [12], [17] and sub-section (1) of the Nigerian Constitution of 1999 also reflects in the National Mental Health Policy (NMHP) of 2013. The NMHP emphasizes the material and social well-being of the Mental Health Service Users (MHSU) through economic participation and rejects discrimination at all levels. However, social acceptance continues to be a daily struggle for the group ${ }^{[1],}{ }^{[12]}$. Decades of studies have pointed to the stigma and discrimination associated with mental illness as threats to the integration of the group [13], [46]. The severity of the disease (negative symptoms and cognitive impairment) as revealed in a comparative study between the United States and European countries $^{44}$ impacts on peoples' acceptance of MHSU. Besides, cultural orientation (values and beliefs) contributes to social distance and the reduced public response to the diseases [7], [12], [28] Contrarily, O'day ${ }^{[26]}$ affirmed that the severity of mental illness, cognitive impairment affects MHSU ability. It stresses the importance of Individual Placement and Supported Employment (IPS) if well planned and funded can bridge the unemployment gap between the MHSU and the general population [14]. However, some MHSU's unemployment are unrelated to the lack of skills or education; for example, $30.1 \%$ of the samples studied by Marwaha et al in Germany, France and the UK possessed post-secondary education and pointed to the local market structure and legal frameworks of the nation as crucial to the understanding problem associated with the employment of MHSU $\left[{ }^{20]}\right.$. Similarly, in New Zealand, nine out of fifteen participants possessed post-secondary qualifications ${ }^{[34]}$. No data exists on affected population or the percentage of the group in the labour market in Nigeria ${ }^{25]}$; however, about 21 million of the Nigerian population is estimated suffering from mental illness $\left[{ }^{16]}\right.$. Additionally, work interventions are linked to the mental healthcare system which can only offer menial jobs ${ }^{[1],}{ }^{[7]}$. Empirical studies on the group participation in the labour market are scarce; available data merely treated it as demographic variables, ${ }^{[1],}{ }^{[24]}$ besides, the dearth of knowledge in this area may also be considered as discrimination. Labour market participation is a fundamental right of all citizenry, and work integration is one of the crucial means of removing socially created barriers between the group and the public ${ }^{[22]}$. Discrimination increasingly imposed restrictions on MHSU even among their close family and the society at large ${ }^{[4][18]}$. European Mental health Alliance ${ }^{[9]}$ raised a concern about the growing presenteeism and absenteeism and early retirement among MHSU. The incompatibility of several Nigerian policies in the manner it addresses mental diseases seems to have endorsed discrimination and legitimatized exclusion. The National Compensation Act ${ }^{[37]}$ makes no provision for MHSU whose illness may be a reoccurring issue which limits intervention for MHSU. This trend is also noticed in the Nigerian Health insurance Act of 1991, which exclude psychological ailments. Again, the federal constitution of Nigeria ${ }^{[41]}$ which endorsed equity for all, restricted MHSU in engaging political services seems to have rendered other policies inefficient since there seems to be no consistency in the structuring of the Nigerian policy. Whether market structure can entirely take responsibility for the treatment of MHSU is a contending issue, when the policy environment 
seems unfavourable to service users. It sets the premise for the review of the literature below.

\subsection{Theoretical framework}

\subsection{Stigma}

Theoretically, stigma is associated with an attribute either physical, social or mental deficiency which can lead to judgmental or socially discriminating attitude towards the bearer of such attribute ${ }^{[10]}$. Stigma leads to social isolation or stereotype. According to Goffman, the stigmatized person can experience self-devaluation, which was termed self-stigma, due to public prejudice (public stigma) and those associated with the stigmatized individual can experience interpersonal stigma due to their close alliance with the sufferer. Yamatani et al. ${ }^{[48]}$ affirmed that societal norms influenced negative attitude towards MHSU, and a change in behaviour starts with rejecting harmful norms and practice. A cross-sectional study by Audu et al $^{[4]}$ in northern Nigeria showed that the knowledge of mental illness between both educated and noneducated persons about the cause of the disease significantly differed. However, such awareness did not reduce discriminating attitudes towards the sufferer. Contrary to the study by Gureje et al. ${ }^{[12]}$ which linked education to positive attitudes and lack of education to negative attitudes towards MHSU. It was affirmed that marriage, education and years of experience reduced bias and discrimination among police officers in Benin City, Nigeria.

Similarly, Gronholm et al. ${ }^{[1]}$ asserted that the experiential view of stigma affects people judgmental attitude and distinctively categories stigma as institutionally-based (lack of legal framework or policies), public stigma (stereotypical behaviour of the general population); interpersonal stigma (stereotypes, based on association with a stigmatized individual); provider-based stigma (experience of discrimination based on one's occupation), and; self-stigma (internalized stigma). Thus, it was suggested that an exploration of intergroup contact and para-social contact could effectively tackle the stigma. Whether such measures can facilitate disclosure at workplaces is arguable, with culture acting as a deterrent to the creation of functional policies and practice. Thus, the fear of dismissal can suppress the desire to open-up about one's mental health status.

\subsection{Conceptual Frameworks}

\subsection{Employment as a right: The Nigerian legal frameworks.}

Work is recognized as inalienable rights of all citizen. According to the International Labour Organization ${ }^{17}$ promotion of the labour participation of all citizens without prejudice is a means to full integration and equity. The Human Rights of 1948 article (23) (1) states that the right to work, freedom to choose employment, equity and favourable working conditions and protection against discrimination is everyone's rights. It stresses the right to equal pay, for the equal job done, and the right to a just, and favourable remuneration to maintain human dignity, and social protection under article (23), (2) (3). Article (25) stresses the right to a standard of living to live a healthy life. However, MHSU rated high among the homeless population ${ }^{[32],}{ }^{[46]}$. The ambiguity in the Nigeria 1999 Constitution and the Labour Act of 2004 about the acceptance and protection of MHSS encourage exploitation in the labour market. Section (12), (17) (1) of the 1999 Federal Constitution of Nigeria states that government social order is built on "freedom equality and social justice." Under sub-section (2) article (a) stresses that "every citizen shall have equality of rights, obligations and opportunities before the law". Again, section (14) on The National ethics reaffirms discipline, integrity, the dignity of Labour, and social justice, among others. However, the notion of inclusion is limited for mental health service user as both section (32) \& (33) strongly object civil participation of this group - these contradictory statements impact on other subsequent policies. The evasiveness of the need for protection of employees with mental health problems against discrimination in the National Labour Act of 2004 has serious implication in the way in which MHSS's need are defined and addressed. The notion of inclusiveness also eludes the construction of the National Insurance Scheme, which attached access to NHIS to employment and its non-inclusion of mental illness among diseases covers. Ode ${ }^{[27]}$ evaluates the response to mental healthcare needs in Benue state to assert that policies are incongruence with needs which legitimatized discrimination of the MHSU.

\subsection{Obstacles in the labour market.}

Problems associated with labour participation of MHSU are tied to personal and societal factors ${ }^{[8]}{ }^{[20]}$. In Canada, at least $90 \%$ of the population are jobless ${ }^{[32]}$ while the Australia Disability Network ${ }^{[3]}$ estimated the rate of unemployment among the group at $83 \%$. Cunningham et al. ${ }^{[8]}$ carried out a qualitative study with twenty study samples. Apart from the discrimination in the workplace, the lack of qualification, the side effect of medication and severity of the illness imposes a more significant challenge on MHSU. In Nigeria, the youth's unemployment rates, estimated at $22 \%{ }^{[25]}$ may be a contributing factor; since organizations have consistently used this avenue to exploit employees, whereby temporary workers can technically remain permanent, temporary workers ${ }^{[29]}$. The World Bank added that the lack of active policy significantly impacts on the labour participation of this group ${ }^{[47]}$.

Again, trust militates against employers' judgement about MSHU's competence ${ }^{[20]}$. A cross-section study in China established that individual managers have negative attitudes toward engaging this group. The concerns about trustworthiness, competence, protection of business image, loss of hours due to time spent convalescing reinforce these negative opinions ${ }^{[6]}$. These studies seem to suggest that the nature of the market can be a significant factor determining the success or failure of MHSU to get engaged or retained in the workplace, which set the premise for this present study. Since most of the reviewed studies seemed to have stemmed from employers' perspectives about the adequacy of MHSU, 
it is imperative to examine service users' perspectives about the problem of access in the Nigerian labour market to contribute to the existing body of knowledge by sharing the peculiar nature of the problem from the perspective of service users. The study took an interpretive phenomenological approach to investigate MHSU's experience of job search.

\subsection{Research Objective}

1. To investigate experience of labeling among MHSU in the labour market

2. To examine MHSU's experience in the course of job search in the Nigeria labour

\subsection{Research Questions}

1. How would you describe people attitude towards MHSU in the labour market?

2. How is your experience of job acceptance in your local community?

\section{RESEARCH DESIGN}

A qualitative research method using an interpretive phenomenological analysis was conducted. Twelve MHSU were interviewed using unstructured interviews method. IPA helped captured the meaning each participant gives to his/her daily struggles ${ }^{[33]}$. Close attention was paid to participants' choice of narratives and the sense they tried to make out of their experience in the local labour market.

\subsection{The Setting of the Study and Procedure for Recruitment}

This study was carried out at Aro neuropsychiatric federal hospital, Abeokuta, Ogun State, Nigeria, one of the eight specialist mental hospitals in Nigeria with an estimated 28,000 service users across West-Africa. The hospital offers rehabilitative care in the form of a sheltered workshop for the patients and provides rehabilitative service offering minimal skills that can only provide menial jobs ${ }^{[28]}$. Ethical approval was granted by the research committee of the Aro Neuropsychiatric hospital Abeokuta, Ogun State, and the University of York, United Kingdom in July and April 2016 respectively. An in-depth interview was conducted at the hospital site (outpatient clinic) which focused on the view and experience of MHSU in the search for job and acceptance in the Nigerian labour market. Two weeks were scheduled for the interview, and each interview session covered 60 to 75 minutes. The first three interviewed were analysed to evaluate the ability of the design to elicit a credible and predictable result. The interview schedule was flexible at the starting point, participants' responses determined interview content and the direction of the questions. Such a design allowed participants to narrate their experiences with a little guide and probing question from the researcher. However, the scope of responses often included accommodation and work in a broader sense, not only about paid employment. The interview session was recorded with the participant's approval which was later transcribed by the researcher and a lecturer at the Department of Linguistics and Language Studies in the
University of Ibadan, Nigeria. The two transcripts were compared, first with each other, second to the recorded copy for accuracy.

\subsection{Participants and Eligibility Criteria}

This study adopted the operationalized definition of severe mental illness specified in the DSM-V for the diagnosis of schizophrenia and bipolar. Using a purposive sampling technique, two nurses at the outpatient clinic helped to identify patients that met the pre-determined characteristics and diagnostic criteria through patients' clinical files. Twelve patients (five females and seven males) who had been in recovery in the past 12 months and between the age of 18 and 35 were selected. Two patients living with bipolar affective disorder, and ten living with schizophrenia were selected. A person with SMI symptoms and comorbid (physical) diseases were excluded to strictly limit the focus to mental illness and employment. A consent form was offered to the family, or the patient, which was returned after it was duly signed. The key to participation is the willingness of the participants and anonymity and confidentiality of the data was maintained throughout the process.

\section{DATA ANALYSIS AND INTERPRETATION}

An interpretative phenomenological analysis of the interview's transcripts was carried out, which responded to open coding. It focused on identifying each participant's experience and the meaning each made of it. The most significant recurrent themes in their narratives and difference in their beliefs, opinions and experiences were identified as suggested by Smith et al. ${ }^{[33]}$. The coding of all the transcripts at the initial reading focused on identifying the demographic variables and themes. The main question served as a guide in developing the coding structure during the second reading phase. New ideas were coded; six themes were generated and further collapsed and categorized into two. Data were read and reread until no further themes were developed. Researcher contacted three of the participants and read the themes to confirm if the identified themes captured their experiences. An illustration of participants' narratives was included to support the themes. This study's motivation stemmed from the practical difficulty that service users often discussed while working within the mental health facilities in Nigeria. As a social worker whose job is to help re-integrate service users back to work after recovery, the obstacles imposed on social-work interventions due to the lack of national frameworks and support influenced how the data is analyzed.

\section{RESULTS}

The table (I) showed details of the socio-demographic variables. Nine participants agreed to be contacted for clarification and interested in receiving the summary of the outcome of the study, only three declined being contacted after the initial interview. 
Table I Indicated the Socio-demographic Variables of the Participants

\begin{tabular}{|c|c|}
\hline & \\
\hline Males & 7 \\
\hline Females & 5 \\
\hline Bipolar & 2 \\
\hline Schizophrenia & 10 \\
\hline Currently Unemployed & 6 \\
\hline Employed (competitive) & 2 \\
Self-employed/part-time & 4 \\
\hline Education: & 3 \\
University & 4 \\
College of educ./polytechnics & 2 \\
Secondary school & 2 \\
Primary & 1 \\
\hline No educational qualification & 1 \\
Ethnicity: Igbo & 11 \\
Yoruba & 0 \\
Hausa & 4 \\
Age: 18-26 & 8 \\
\hline 27-35 &
\end{tabular}

\section{Hostility:}

The notion of hatred pervaded participants' opinions of public attitude towards service users. Participants felt that the misconception about the cause of mental illness contributes to the observed hostility. This negative attitude reflects not only in their interpersonal relationships but also in the workplace (attitude of the colleagues and supervisors) towards the sufferer. Disclosure becomes problematic due to the fear of being labelled as 'insane person' and losing the source of income if their condition is known. Despite, participants seem to have a sense of resilience and optimistic view in their struggle to adjust to the hostile environment. Three subthemes included are (a) discrimination "once mad is always mad", (b) suffering in silence/ (c) lack of support.

\section{(a). Discrimination:}

Tendency to discriminate is felt not only in public eyes but also in participants' interpersonal relationships. There seemed to be mixed feeling and confusion in their description of the family understanding of the disease, which impacts on family interactions with the sufferer. Crate (pseudonym) stated her ordeal as followed.

"I was in my second year at the polytechnic when this illness first started, so I have to put my education on hold. My parents did not understand the problem at the start of it. They chained me down, asked my younger sibling to beat me up, and I was starved for days. (How did you feel?). I don't think they did it intentionally; it is out of complete ignorance about my condition. ... It was only after several failed attempts that we were directed to this hospital, and I have been stable since then, except for occasional tiredness which I was told is normal for someone taking this kind of medication. Though the specialists have helped clear some of my doubts, I'm still left with a thousand unanswered questions. It took me four years to complete two years diploma programme, and I did a secretarial job for a while, but right now, I am helping my mother to run her restaurant. (Why did you quit your previous job?). oh, it has nothing to do with the illness, I was a secretary to a gubernatorial candidate, so when the campaign ended, so also was the office and my appointment got terminated. But getting a job for a person without ailment is difficult in this country. Not to talk of someone like me.... I am working in my family's restaurant even with that, many of our workers still stared oddly at me, as if what I have is contagious."

There is a sense that a person with mental illness cannot recover as a result is incapable of contributing to the economy as noted by a participant "once mad is always mad" in public eyes. It is obvious that mental illness is challenging and can set the sufferers back from reaching their goals but through perseverance and encouragement the individuals can reach their full potential.

\section{(b) Suffering in silence}

The experience of negative attitude reduces confidence to participate in social interactions and increases complexity in interpersonal relationships, the constant feeling of being misunderstood or prejudiced sometimes results in less desire to communicate their feelings or share their opinions. Sky (pseudonym) said.

"God helps you if you are down with this kind of ailment; even the wife you married will mock you. Whether you're suffering or happy, you don't get to talk about it for fear of being scorned. If you laugh too much, they will misinterpret, your sadness will drive them to the same conclusion..."

Thus, participants daily experience embodied discrimination due to derogatory local language such as madness "asinwin" and insanity "were" (local languages) used in defining them. Participants are conscious of the limitation it imposes on their hope and aspiration in economic participation.

\section{(c) Employment as a favour, and not one's right}

At the place of work, participants described the perceived negative attitude which comes in the form of open rejection, ostracization and dismissal. It impacts on disclosure of mental health status and reduces participants' self-esteem. The knowledge of high unemployment rates and the lack of support from the government by the participants seemed to reinforce their fear of what might be the consequence of declaring their mental health status. Job is not described as a right but a "favour" due to their mental health condition. Lemon (pseudonym) stated that:

"there is simply no job out there when you do get one, for someone like me, you have to pretend to fit in. The day your employer or colleagues know about your 
condition, that's the day you lose your self-respect. You know, I once taught at a Nursery school, due to my sickness, .., the proprietor paid me lesser (sic) than my co-workers, and later sacked me (why were you sacked?), I fought with him over the lack of sincerity and the continuous abuse not only from him but also from my colleagues..., I think, to him, offering me a job is like doing me a favour..".

\section{Exploitation due to institutional barriers}

Participants are aware of the lack of jobs in the labour market and the exploitation due to the peculiarity of their situation, the lack of active policy and high unemployment rate. The critical issues that were paid attention to in participants' narrative are: (a) the dilemma of disclosure at workplace (b) stigma and loss of dignity (c) the link between general unemployment and MHSU' predicament which lead to unceasing exploitation. Blue (pseudonym) expressed his fear as followed:

"You know, I recently got hired as a casual staff in public service (name withheld). I have not been staffed; it will be six months in August that I have been working there. It is becoming tough for me. (Why?) because I am working night shift which is incompatible with my condition and I am extremely afraid to complain to my immediate supervisor.... About two months ago, I complained to my care team; they agreed that switching and alternating my medications might enable me to cope at night. Right now, I switched the evening medication for the morning so that I can rest during the day. My body is yet to get used to it; I always feel like napping and sometimes becomes fidgeting; I still struggle to stay awake. I am struggling to cope, and I do not want to give my colleagues any negative impression of me. (Why?) I have lost one in the past due to this same issue and being mocked for it. People can choose to be mean; I was laid off even while still receiving treatment. It took me several years to finally get this one. I don't want to experience such ordeal again. ..."

\section{(b). Opportunities are confined to close network.}

There seemed to be a sense of awareness among participants about the complexity arising from the high unemployment rate in the country and the lack of active institutional framework which encourages exploitation. Although, the National Labour Act, 2004, Trade policy 2005, National Mental Policy 2013 and Employees Compensation Act 2010 are set to guide against exploitation and unfair treatment; MHSU are aware of the existence of some of these policies and its inability to guard against exploitation. Participants agreed that they had to look inside their own circle for support either career-wise or financially. One of the most significant problem for this group (especially male) was employment which was defined as a means to accomplishing one's aspiration; such as being married, living an independent life and taking control over ones' lives. The inability to earn a living remained an unfulfilled yearning in their lives.

Race (pseudonym) stated that: " I have a degree in business administration, and I was so lucky, as soon as I graduated, I got a job which I actually loved (I was an accountant). I think my problem started when I got laid off, and ever since then, things have not been okay. I mean, things are okay for me, but I still feel depressed sometimes. Thinking about what my life could have been, don't get me wrong ... (why were you sacked?). If you work in a banking system, it is inevitable, I just felt, I didn't deserve such a fate with all my effort, ... it is awful. I think it was a realization of what my ailment meant for my family that made me carved another path. I am self-employed now, a contractor, and I have my father to thank for it. You know in this country to do this kind of business; you definitely need strong supports. (How exactly do you get your support?)... Mainly from my family, I mean my father is quite a prominent person, he helped me a lot, but I help him too by doing a good job, you can say that I am selfpromoting myself... . My family are very understanding and supportive. "

\section{(c). Accommodation problems.}

Homelessness was never anticipated but became an issue which was tied to the lack of economic participation. Participants described homelessness as a contending issue affecting them and was linked to unemployment, and family hostility (sufferer may be sent away from home due to his/her ill health), they are also conscious of the lack of government support in this area. Baobab (pseudonym) described his experience in this manner:

"people with HIV received more support than us, I cannot name how many time in the past that I have been ejected from my rented home, even in the family house that I now live, my wife and children are constantly victimized. I think they are looking for every means to drive us out. (Why do you think people behave this way?). I can't say for others, but in my family, I think they are ashamed of my condition and do not want to associate with me. (What do you think could be done to help?). Nothing can be done unless the government gets involved, (how?), By providing low-income housing, granting financial support or help through drug subsidy. We are on our own, and people's attitudes are just getting worse..."

\section{DISCUSSION}

This study explored problems of engagement for MHSU in the Nigerian labour market. MHSU's experience of job search is crowded with negativity, they seemed to perceive societal attitudes towards them as detrimental to their integration. Participants consistently used expressions like "unfit and incompetent" to capture societal attitudes towards them as 
well as in their interpersonal relationships. A declaration of one's mental health status could alter existing relationships, debar a new relationship and hindered employment opportunities; Marwaha and Johnson's ${ }^{4}$ reported similar outcome, asserting that disclosure and staying employed hostile working environment often contributed to MHSU's decision to quit jobs. Secrecy seemed to be embraced as opposed to disclosure in the workplace. Even among the selfemployed, there is a sense of reluctance to admit their mental health status publicly; participants were conscious of the "disdain and serious hostility" ever-present in both personal and public relationships.

Poor knowledge of mental illness and recovery, culture and norms of society contributed to the observed negative attitudes in service users' interpersonal relationship, and at the workplace. It plays out the significance of phrase like "once mad is always mad" as captured in participant's narrative, which is in line with Audu et al.' ${ }^{[19]}$ findings, suggesting that inadequate knowledge about the cause and prognosis of the diseases encourages stigma and social distance even among the educated people. Contrarily, Thokagevistk et al. ${ }^{[44]}$ seemed to articulate that it is the severity (cognitive and negative symptoms) of the diseases that impact on employers' judgement about MHSU's competence or trustworthiness. Given the knowledge of this current finding and the previous studies, it is vital to question the contents of the National Employment Scheme ${ }^{38}$ and its mode of delivery which failed to consider the dilemma of labelling and disclosure in a society with a $22.5 \%$ youths unemployment ${ }^{[25]}$. The policy does not account for differences in disability and interests since it muddles the employment of service users with the general population, as if needs, choice and opportunity are the same.

The low involvement of the government as articulated in this by participants showed that they are aware of the government's aloofness to their plights which reinforced Ogunlesi ${ }^{[28]}$ views on the lack of active policy and support to aid work integration of this group. The inconsistency in the broader Nigerian policies highlights how problematic the situation has become. Not only did the section (32) and (33) of Nigerian constitutions prohibits persons with mental illness from participating in a political career, the use of discriminating word like "insane" endorses discrimination. Also, the prohibition of discrimination in this legal framework excludes mental illness. Notwithstanding, the National Mental Health policy ${ }^{[42]}$ articulates tackling discrimination at workplace, its inadequacy can be tailed to the broader legal frameworks which limit social integration of MHSU. This complexity also enunciated in the mode of delivering the National Insurance Scheme of 1991 as employment is the only yardstick of accessing it. Besides, only $4 \%$ of the population (Federal Government employees) are covered and major psychiatric illnesses are not covered in the scheme. Such extreme negligence is also observed in the deliberate exclusion of pre-existing mental health condition in the
National Labour Law of 2004 and the Trade Amendment Act of 2005. A reminder that problems associated with social integration and protection of MHSU are deeply rooted in the cultural perception of the diseases and institutional frameworks.

At least two respondents suggested that tiredness, low-selfesteem and side effect of medication (drowsiness and fidgeting) increased internalized stigma and affected their confidence to search for jobs which reinforced Huggett et al.' ${ }^{[13]}$ about the impact of internalized stigma on MHSU on their confidence. Nonetheless, eight of the participants felt that the lack of support is significant, and high unemployment rates affect their labour participation. Though O'day, et al. ${ }^{[26]}$ asserted that the severity of mental illness militates against the active engagement of MHSU, in this study, regardless of the severity of the diseases, participants are willing to work, provided the job is not strenuous.

\section{CONCLUSION}

In this study, an exploration of MHSU's experiences in the Nigerian labour market was conducted. It was evident that participants are aware that cultural perceptions and the lack of active institutional frameworks militate against their social integration and opportunities. It impacts on how mental health service users' needs are constructed and addressed. Thus, close networks remain significant to service users in accessing the labour market and in providing financial support. This support comes in various ways, such as the provision of financial assistant to start a trade, sourcing for customers to patronize their loved one's businesses, or helping them negotiate contracts. Self-understanding and optimism are suggested as their adaptive coping skills to face social rejection in their daily lives. Even though employment is desirable to service users, living in a highly stigmatized environment seemed to have given them an understanding of the danger of raising a false hope with no government support. The study has an implication for social work practice in advocating for policy of inclusion for MHSU. For a better explanatory model, further investigation needs to focus on how cultural influence can affect broader policy plan and the modality for selecting a good work model in promoting economic participation of MHSU.

\section{Study Limitation}

A major challenge to this study is timing; most patients lived outskirts of the city and were on monthly appointments. Since the interview was scheduled for two weeks, on the spot recruitment was conducted. Outpatient clinic day is twice a week, which means that patients may not be seen until the next appointment. Thus, both the consent forms and the interview took place consecutively. Due to this inflexibility, only patients at the outpatient clinic were reached, which reduced the heterogeneity of the population studied. Also, only participants that agreed to be contacted were called for further clarification. Future research in this area may need to consider these issues to prepare ahead or alternatively use 
WebEx conference or zoom, however, the constant power failure may pose a challenge to this medium.

\section{Future Research}

There is a need for an extensive study in this area, and the present finding may act as a guide for the national research study. Again, the nature of the support was not adequately explored in this study, future studies may need to focus on the complexity inherent within the network system and how it can impact on the structure of power.

\section{DECLARATION}

No conflict of self-interest.

\section{REFERENCES}

[1] Adebowale TO, Onofa LU, Sowunmi O, Majekodunmi OE, Latona OO, \& Akinhanmi AO. (2014). Outcomes of care among patients admitted to the rehabilitation unit of a specialist Neuropsychiatric Hospital in Nigeria. Global Journal of Medical Research: A Neurology and Nervous Sys, 14(3),1-8. http://creativecommons.org/licenses/by-nc/3.0/

[2] American Psychiatric Association (2013). The diagnostic and statistical manual of mental disorders, DSM-5.

[3] Australia Network on Disability (2019). Disability statistics. Retrieved 22/10/2019. https://www.and.org.au/pages/disabilitystatistics.html

[4] Audu IA, Idris SH, Olisah VO et al. (2011) Stigmatization of People with Mental Illness among Inhabitants of a Rural Community in Northern Nigeria. Int. J. of Social Psychiatry, 59, 55-60. https://doi.org/10.1177/0020764011423180

[5] Bond, G. R. (2004). Supported employment: Evidence for an evidence-based practice. Psychiatrie Rehabilitation Journal, 27, 345-359.

[6] Chan JY, Hirai HW, \& Tsoi KK. (2015). Can computer-assisted cognitive remediation improve employment and productivity outcomes of patients with severe mental illness? A meta-analysis of prospective controlled trials RSS. Journal of Psychiatric Research, 68, 293-300.

[7] Darius ME, Paul G, Alain M, Prefina M, Ondzotto G, Honoré N, Jean-Rosaire I. (2020). Working in psychiatry: Staff perception of the Brazzaville hospital and University Center, Open J. Psychiatry, 10(2), 39-44 DOI: 10.4236/ojpsych.2020.102005

[8] Cunningham K, Wolbert R, \& Brockmeier MB. (2000). Moving beyond the illness: Factors contributing to gaining and maintaining employment. American J. Community Psychology, 28(4), 481-494.

[9] EAMH. (2018). Mental health and employment-related issues: Recommendations from European Mental Health Alliance: Employment \& Work. Retrieved 02/7/2019. https://ec.europa.eu/health/sites/health/files/mental_health/docs/co mpass2017 workplace en.pdf

[10] Goffman E. (1963). Stigma; notes on the management of spoiled identity. Englewood Cliffs, New Jersey, Prentice-Hall.

[11] Gronholm P., Henderson C., Deb T, \& Thornicroft G. (2017). Interventions to reduce discrimination and stigma: The state of the art. Social Psychiatry and Psychiatric Epidemiology, 52, 249-258. https://doi.org/10.1007/s00127-017-1341-9

[12] Gureje O, Lasebikan VO, Ephram-Oluwagbemiga O, Olley B.O, \& Kola L. (2005). Community study of knowledge of and attitude to mental illness in Nigeria to mental illness in Nigeria. A British Journal of Psychiatry, 186, 436- 441.

[13] Huggett C. Birtel DM, Awenat YF, Fleming P, Wilkes S, Williams S, \& Haddock G. (2018). A qualitative study: Experiences of stigma by people with mental health problems. Psych, and Psychotherapy: Theory, Research and Practice, 91, 380-397. DOI:10.1111/papt.1216

[14] Hutchinson J, Gilbert D, Papworth R, \& Boardman J. (2018). Implementing supported employment. Lessons from the Making
IPS Work Project. International journal of environmental research $\begin{array}{lll}\text { and } \quad \text { health, } & 15(7),\end{array}$ https://doi.org/10.3390/ijerph15071545

[15] Human Right Watcher. World Report (2014). Nigeria. Retrieved 28/02/2020. https://www.hrw.org/world-report/2014/countrychapters/nigeria

[16] Ifijeh M. (2015, February 19). Nigeria: 21 Million Nigerians have psychiatric disorder. Nigeria, All Africa: This Day. Retrieved 1/05/ 2017. http://allafrica.com/stories/201502191101.html

[17] ILO Modelled Estimates. World employment and social Outlook Trends 2020, International Labour Law, ILO.

[18] Kane JC, Elafros MA, Murray SM, Mitchell EMH. Augustunavicius J., Causvic S, \& Baral SD. (2019). A scoping review of health-related stigma outcomes for high-burden diseases in low- and middle-income countries. BMC Med 17, 17. https://doi.org/10.1186/s12916-019-1250-8

[19] Marwaha, S., \& Johnson, S. (2005). Views and experiences of employment among people with psychosis: A qualitative descriptive study. International Journal of Social Psychiatry, 51(4), 302-314.

[20] Marwaha S, Johnson S, Bebington P, Stafford M, Angermeyer MC, Brugha T, Azorin JM, Kilian R, Hansen K, \& Toumi, M. (2009). Predictors of employment status change over 2 years in people with schizophrenia living in Europe. Epidemiology Psychiatric Social Science, 18(4), $344 \quad-351$ https://doi.org/10.1017/S1121189X00000324

[21] Magliano L, Read J, Oliverio, SN, D'Ambrosio A, Campitiello F, Zaccaro AM, Guizzaro, L, \& Patalano M. (2014).Social dangerousness and incurability in schizophrenia. Results of an educational intervention for medical and psychology students. Journal of Psychiatry Research, 219 (9), 457-463

[22] Marotoa M, \& Pettinicchio D. (2014). Disability, structural inequality, and work: The influence of occupational segregation on earnings for people with different disabilities. Research in Social Stratification and Mobilities, 28, 76-92. DOI 10.1007/s10926013-9426-0

[23] Morris BD, Holly L, Brian P, \& Jason JK. (2018). Comparison of focused cognitive training and portable "brain-games" on functional outcomes for vocational rehabilitation participants. Scientific Reports, 1(8), 1779- 1788. doi.10.1038/s41598-01820094-w

[24] Mosanya TJ, Adelufosi AO, Adebowale OT, Ogunwale A. \& Adebayo OK. (2013). Self-stigma, quality of life and schizophrenia: an outpatient clinic survey in Nigeria, Int $J$. of Social Psych, $60(4), \quad 377-386$ https://doi.org/10.1177/0020764013491738

[25] National Bureau of Statistics (2019). Unemployment 2019-Q1. NBS Bulletin. Retrieved 14/09/2019,https://www.nbs.gov.sc/downloads/social/unemploym entstatistics/2019

[26] O'day, B., Kleinman, R., Fischer, B., Morris, E., \& Blyler, C. (2017). Preventing unemployment and disability benefit receipt among people with mental illness: Evidence review and policy significance. Psychiatric Rehab. J, 40(2), 123-152. https://doi.org/10.1037/prj0000253

[27] Ode, P. (2017). Voices from the field: Mental health and primary care in Benue State, Nigeria. Mental Health Innovators: The Department of Mental Health and Substance Abuse: World Health Organisation, Geneva.

[28] Ogunlesi AO. (2008). Aro Village. Bulletin of the Neuropsychiatric hospital Aro, Abeokuta, Bulletin, 4 (1), 14-17.

[29] Otuturu GG. (2014). Labour law review NJLIR Vol. 8 NO. 4, 2014: Trade unions amendment Act (2005) and the right to strike, an international perspective. Department of Legal Studies, Bayelsa State College of Arts and Science, Elebele, Yenagoa, Nigeria and Principal Partner, Crown Chambers, Yenagoa.

[30] Owadara FO. (2015). Perception of young adult with first episode of schizophrenia on access to employment in Aro Neuropsychiatric Hospital Abeokuta Ogun State. A Master Thesis Submitted to Department of Social Work and Social Policy, University of York, United Kingdom. 
[31] Piwuna CG. (2010). Mental health and employment. Nigerian J. of Med. 19(1), 1-8.

[32] Poremski D, Distasio J, Hwang S, \& Latimer E. (2015). Employment and income of people who experience mental illness and homelessness in a large Canadian sample. The Canadian Journal of Psychiatry, 60(9), 379-385. https://doi.org/10.1177/070674371506000902

[33] Smith JK, Flowers P, \& Larkins M. (2009). Interpretive phenomenological analysis(2nd, ed.). London: Sage.

[34] Southern, A. (2010). Career interrupted? Psychiatric illness and women's career development in Aotearoa/New Zealand. A Doctoral Thesis Submitted to the Department of Health Sciences. University of Canterbury.

[35] The Universal Declaration of Human Rights (UDHR) 1948. Retrieved 30/03/20. https://www.un.org/en/universal-declarationhuman-rights/

[36] The National Labour Act, L1. Law of the Federation of Nigeria 2004 (Labour Act). Federal Ministry of Labour and Productivity.

[37] The National Employees Compensation Act 2010. FRN

[38] The National Employment Scheme, 2017. FRN.

[39] Trade Act T14, 2004 as amended by Trade Union (Amendment) Act 2005. Federal Ministry of Trade and Commerce.

[40] The National Health Insurance Scheme, Act N42, LFN 2004. Federal Ministry of Health
[41] The Federal Constitution of Federal Republic of Nigeria 1999. FRN

[42] The National Mental Health Policy 2013. Federal Ministry of Health.

[43] The Federal Ministry of Justice, Abuja. Constitution of the Federal Republic of Nigeria, 1999. Retrieved 28/02/2020. https://www.refworld.org/pdfid/44e344fa4.pdf

[44] Thokagevistk K, Millier A, Lenert L, Sadikhov S, Moreno S, \& Toumi M. (2016). Validation of disease states in schizophrenia: comparison of cluster analysis between US and European populations. J. Market access \& Health $P, \quad 4$, 10.3402/jmahp.v4.30725. https://doi.org/10.3402/jmahp.v4.30725

[45] US. Department of Labour (2018). Persons with a disability: Labour force characteristics. Bureau of Labour Statistics, BLS.

[46] Waghorn G, \& Lloyd C. (2005). The employment of people with mental illness. Australian e-Journal for the Advancement of Mental Health, 4(2),1-10. Doi: https://doi.org/10.5172/jamh.4.2.129

[47] World Bank (2014). Growth, inequality, and social welfare: Cross-Country evidence, DC, World Bank Press.

[48] Yamatani H, Teixeira S, \& McDonough K. (2015). Employing people with disabilities: a preliminary assessment of a start-up initiative, Journal of Human Behavior in the Social Environment, $\quad 25: 8, \quad 830-842, \quad$ DOI: $10.1080 / 10911359.2015 .1028261$ 